Est Ag 44 (2009) 5-33

\title{
Hablar hoy de Dios y testimoniarlor
}

Nunca ha resultado tan importante hablar de Dios, y lo que es aún más apremiante, testimoniarlo, como hoy. De hecho, en el momento presente, Dios constituye la realidad mayor de la teología y la preocupación principal de las religiones. El Ser Supremo está llamado a convertirse, también, en el contenido prioritario de la predicación de la Iglesia y en la tarea primordial de la espiritualidad cristiana. Necesitamos testimoniar a Dios con más convencimiento interior y testimonio exterior que nunca, sobre todo en Occidente. Y para ello apremia, también, vivificar en cada uno de nosotros la experiencia de Dios, que no se contente con la simple exposición del tema, sino que también implique la propia vida.

Urge centrar nuestros esfuerzos evangelizadores en este tema, porque Dios y su reinado están ausentes de la vida de muchos compatriotas nuestros. No aparecen en la cultura actual, tan rica y polifacética en otros aspectos. Cada vez resulta más difícil encontrar alusiones a la trascendencia en los medios de comunicación, tan abiertos a los más diferentes aspectos humanos. Comprobamos con asombro que se margina la presencia divina en las grandes manifestaciones artísticas. La misión de la Iglesia, y con ella la misión de sus miembros más cualificados, consiste entonces en presentar ante el mundo la buena noticia referente a Dios tanto en teoría como en praxis, sobre todo en la verificación práctica de la vida diaria.

Hubo un tiempo, cuando Europa estaba desunida por las guerras y se desangraba en luchas intestinas, que no había más remedio que predicar la reconciliación entre los grupos sociales, desgastarse por la implantación de los derechos humanos, alzar la voz a favor de la dignidad de la persona humana, apostar por la fraternidad entre los pueblos. Por eso la Iglesia construyó toda una cultura sobre el hombre y su destino. Aparecieron los distintos huma-

\footnotetext{
${ }^{1}$ Este texto contiene una conferencia, dirigida al gran público, en el marco de unas Jornadas de Teología, preparadas en el mes de marzo de 2007, por el Instituto Teológico del Seminario Mayor de Palencia.
} 
nismos con el esfuerzo de muchos y después de ingentes tanteos se fueron formando comunidades nacionales conexionadas, abiertas a la reconciliación. Se enalteció lo humano con todo lo que comporta y se pudo construir un mundo mejor, siempre con sus luces y sombras, como toda conquista humana.

Hubo un tiempo, también, en que la Iglesia tuvo que predicar a Cristo, ya que se corría el peligro de que su persona y enseñanza cayeran en el olvido o que su vida y obra fueran malinterpretadas. Sus miembros más concienciados recordaron así el puesto del Señor como imprescindible en el cristianismo. La especificidad creyente no podía desarrollarse sin la correcta intelección de la persona de Jesús, la vivencia cristiana podía esfumarse sin la práctica de sus enseñanzas, la acogida de su estilo de vida y la implicación comunitaria en su destino.

En el tiempo del Concilio, allá por los años sesenta del siglo XX que muchos de los aquí presentes vivimos, la Iglesia planteó su propio misterio, dialogando consigo misma y abriéndose al mundo, para poder ser más eficaz en la presentación del mensaje de salvación en fidelidad a su Señor. Trató de acreditarse ante la sociedad como luz, sal y fermento para el servicio de la humanidad entera. Se sintió obligada a autodefinirse como «sacramento universal de salvación» ${ }^{2}$, ya que no pocos pretendían separarla de Cristo y hacerle irrelevante, desgajándola de su savia más fecunda.

Hoy la situación ha cambiado radicalmente, ya que es nada menos que Dios quien se encuentra amenazado, incluso puede desaparecer del mundo en que vivimos, si no atajamos la situación en la forma debida. Da la sensación que el hombre, más que intentar justificarse ante Dios, vive al margen de Él y en ocasiones hasta tiene la osadía de pedirle cuentas, porque le desagrada su posible modo de proceder. Nos hemos endiosado tanto que parece que es Dios quien tiene que justificarse ante el hombre y explicar su comportamiento, que no es entendido, cuando no rechazado.

El Ser Supremo, que todo lo sustenta, el Creador del mundo, que todo lo hizo bien, el Salvador de la humanidad por medio de su Hijo Jesucristo, ha dejado de ser acogido, reconocido y amado. Sin pretender ser catastrofista conviene reconocer que Dios está completamente olvidado en anchas capas crecientes de la sociedad. Cunde la desafección religiosa, se extiende la increencia, no deja de surgir el ateísmo teórico y práctico en formas más o menos virulentas. Los avances tecnológicos, las fantasías propiciadas por los

\footnotetext{
${ }^{2}$ Así afirma literalmente el Concilio: «Y porque la Iglesia es en Cristo como un sacramento, o sea signo e instrumento de la unión íntima con Dios y de la unidad de todo el género humano, ella se propone presentar a sus fieles y a todo el mundo con mayor precisión su naturaleza y su misión universal» (LG 1).
} 
medios de difusión parecen querer sustituirlo en el corazón de los humanos y en la nostalgia de sus deseos.

Por eso Dios, así como suena, representa hoy la gran bandera que la Iglesia tiene que alzar en medio del mundo. Sólo desde la experiencia sincera y el testimonio convincente de Dios podrá la comunidad de Jesús salir al paso del indiferentismo religioso existente, que no pronostica bienes, sino todo lo contrario, la deshumanización de la sociedad. La ausencia de Dios constituye una de las mayores tragedias de la sociedad actual. El tiempo en que estamos inmersos, puede ser un momento muy propicio para tomar conciencia de la gravedad de la situación y obrar en consecuencia. No se trata de perder la ilusión en el camino, más bien se trata de comunicar la esperanza a los demás, siendo conscientes de lo que nos traemos entre manos y la tarea que a todos nos aúna.

Hace muy poco, resulta gratificante coincidir con él, ha escrito BENEDICTO XVI:

«La Iglesia debe hablar de muchas cosas: de todas las cuestiones relacionadas con el ser humano, de su propia estructura y ordenamiento. Pero su tema auténtico, y en cierto sentido único, es "Dios". Y el gran problema de Occidente es precisamente el olvido de Dios, un olvido que no deja de extenderse. En definitiva, todos los problemas concretos pueden reconducirse a esta pregunta; estoy convencido de ello» ${ }^{3}$.

Partimos entonces de este convencimiento, hecho experiencia sentida: Dios no constituye un asunto entre otros en el ser y quehacer del hombre. Más bien significa, de hecho, la cuestión central de su existencia. Dios es Alguien, que le importa de manera absoluta al hombre, de modo que no puede descubrir quién es, hacia dónde se encamina, cuál es el sentido de su vida y cómo puede llegar a lograrla, si prescinde de quien se encuentra en su origen y destino. Estos comprometidos planteamientos no pueden considerarse superfluos e inútiles - como algunos pretenden convencernos de ello-, sino temas vitales de primera trascendencia, detrás de los cuales irrumpe la pregunta sobre Dios, sentido último tanto del hombre como del mundo.

La pastoral tiene una encomienda sagrada que no puede eludir y mucho menos en el presente. Hacer que la experiencia de Dios resulte hoy también posible. «Una cosa sigue siendo cierta - escribió en su día K. RAHNER - que el ser humano puede experimentar a Dios. Y nuestra pastoral debería siem-

${ }^{3}$ Discurso de BENEDICTO XVI a la Curia Romana ante la Navidad (22-12-2006): Ecclesia 3.343-44 (6 y 13 de enero de 2007) 41. 
pre y en cualquier circunstancia tener presente esta meta inexorable» ${ }^{4}$. Lo verdaderamente consolador está en que Jesús, precediéndonos con la fuerza de su testimonio, nos ha ayudado a experimentar a Dios en su verdad, bondad y belleza como nadie lo había hecho antes y como nadie lo hará después de Él jamás.

Los sacerdotes y agentes de la pastoral más directa estamos llamados a poner alma, vida y corazón, para que se den las condiciones necesarias en orden a que esa experiencia pueda hacerse realidad en cada cristiano. Los creyentes más concienciados están llamados a tomar muy en serio su responsabilidad como testigos del Dios vivo en medio del quehacer cotidiano. Un cristiano sólo se hace, cuando va creciendo en su vida la experiencia de Dios, tal como la ha mostrado Cristo, y sabe transmitirla con el gozo de la parresía.

El cristianismo se acredita como una religión que busca ofrecer al hombre la felicidad que ha irrumpido en la historia con el acontecimiento Cristo. Tendrá futuro y podrá convencer al hombre moderno en la medida que brinde la oportunidad a cada creyente de ser feliz primero en esta vida y adquirir la bienaventuranza eterna en el día final. Todos buscamos la felicidad y la Iglesia nos plantea esta alternativa: o la encontramos en el Cristo bendito, que nos abre a Dios o nunca la encontraremos, siempre teniendo en cuenta que en este mundo nunca podemos alcanzar la felicidad definitiva. Ésta no puede ser resultado de la actividad humana, sino regalo del Señor en el más allá de la muerte, en la vida bienaventurada.

Mi propósito, con palabras de la Escritura es bien claro: dejemos «que se manifieste Jesucristo, al que no habéis visto todavía, pero en el que creéis y por lo tanto amáis, alegrándoos con un gozo inefable y glorificador. Alcanzaréis así la salvación, que es el objetivo de vuestra fe» $(1$ Pe 1,8). Precisamente es Jesucristo, quien nos muestra al verdadero Dios y con la fuerza de su Espíritu quien nos enseña a testimoniarlo.

\section{Punto de partida}

Parto de una constatación: existe en el hombre normal algo más fuerte que su propia voluntad, algo que se impone incluso al deseo de cualquier signo, es la fuerza misteriosa de la presencia de Dios, que actúa en su vida

\footnotetext{
${ }^{4}$ Cf. Homilética. Sal Terrae (2007/3) 273.
} 
como principio incoercible. Se instala tan dentro de cada persona que una y otra vez aparece en su interior, sin posibilidad de poder desterrarla de sí, por mucho que lo pretenda. Es verdad que Dios se nos revela, a la vez, como presencia y ocultamiento, que nunca aparece con la claridad que nos proporcionan las cosas que nos entran por los sentidos físicos. Y es verdad, del mismo modo, que pueden darse circunstancias coyunturales que impiden al hombre el encuentro con Dios durante gran parte de su vida, incluso durante toda su vida. Piénsese en personas que hayan nacido, crecido y vivido en regímenes ateos. Pero me parece que entre nosotros en muy contadas ocasiones, si es que se da alguna, pueden producirse tales casos.

Por eso en estas latitudes, ese Dios escondido, cuando tenemos el corazón en su sitio y dejamos hablar a la propia conciencia, se impone de tal manera que, en circunstancias normales, cuanto más lo intentamos alejar de nuestros intereses vitales, más se introduce en el santuario interior. Sin duda el hombre podrá decir no a Dios por la causa que sea, podrá reprimirlo en lo más íntimo de su interior, pero llegará un momento, es más se darán muchos momentos, en que Dios vuelva una y otra vez a él y no tendrá más remedio que encararse con su presencia, para afirmarla o rechazarla. SAN AGUSTín expresó de forma magistral este hecho humano mayor y primario, al comienzo de su libro más conocido:

«Grande eres, Señor, y sumamente laudable; grande es tu poder y tu sabiduría no tiene número $[\ldots]$, porque nos has hecho para ti y nuestro corazón está inquieto hasta que descanse en ti» 5 .

5 «Magnus es, Domine, et laudabilis valde; magna virtus tua et sapientiae tuae non est numerus [...], quia feciste nos ad te et inquietum est cor nostrum, donec requiescat in te»: Confesiones $\mathrm{I}$, I,1. Obras de San Agustín Tomo II (BAC 11; Madrid 1946) 324s. Sin duda ha sido Agustín DE HIPONA quien ha encontrado una formulación más bella. Pero antes y después de él, tanto paganos como cristianos, han mantenido una tesis semejante a la suya. Afirma el Maestro ECKHART: «Cicerón y Séneca dicen también que ningún alma racional está privada de Dios. La semilla de Dios está en nosotros [...] Orígenes, un gran doctor, nos dice: "Como es el mismo Dios el que ha sembrado en nosotros, por mucho que se la cubra o esconda, no se llegará nunca a destruirla totalmente ni a apagarla; ella continúa ardiendo y brillando, sin cesar luciendo y resplandeciendo y tiende siempre a elevarse hacia Dios"》 (Maestro ECKHART, Obras escogidas [Barcelona 1980; Visión Libros] 22s). En la teología actual W. PANNENBERG ha llegado a establecer esta provocativa tesis: «Hablar responsablemente de Dios es relacionarlo con todo lo que acontece. La revelación no se realiza en la historia, sino como historia. Es decir, no se manifiesta en determinados acontecimientos aislados, sino en todo lo que ocurre» (M. FRAIJO, «Wolfhart Pannenberg: ¿Quién teme a la razón? Cristianismo y argumentación»: Sal Terrae 84 (1997) 592s. Sostiene el famoso teólogo: «Los acontecimientos en los que Dios ha revelado su divinidad son, considerados dentro del contexto histórico, evidentes por sí mismos [...] Considerada en sí misma, la verdad de Dios es evidente» (W.PANNENBERG, La revelación como historia (Salamanca 1977; Sígueme) 127. Si Dios se muestra de forma evidente en la historia, cuánto más se manifiesta en el mismo hombre. 
Esto significa que no tenemos que tener miedo a hablar de Dios. No se trata de engatusar a la gente, como quien vende un producto cuya fecha de caducidad ha pasado ${ }^{6}$. No. Se trata de enfrentar al hombre con algo que es parte substancial de él y conviene a lo más sagrado de su esencia. Dios pertenece de lleno a la estructura humana y el que prescinde de Él está echando a perder un componente básico de su condición humana. Prescindir de la pregunta sobre Dios en el hombre conlleva cercenar algo de capital importancia para el desarrollo y destino de la familia humana.

Es hora de que los creyentes disipemos los complejos y demos razón de lo que podemos y queremos testimoniar: la religión no quita, confiere humanidad. «Religa» al hombre a Dios, para liberarlo de ídolos y fantasmas, que amenazan su desarrollo. El cristianismo no se muestra como un absurdo en la sociedad actual de tantos avances científicos, más bien confiere sentido a la existencia por medio de la acogida de la fe, la práctica del amor y la apertura a la esperanza. Fe, amor y esperanza no constituyen quimeras sin ningún contenido objetivo, sino dimensiones gratificantes de la condición humana, que le abren a la ultimidad hacia la que tiende el ser humano.

San Juan de la Cruz, que sabía mucho de espiritualidad mediante una experiencia probada, definió a Dios con gran acierto como «la Realidad realmente verdadera». En la búsqueda del principio primero de lo existente se alza Dios como acontecimiento mayor indiscutible. Dios no sólo es la realidad primera, también la más necesaria, la que sostiene la vida creada y confiere futuro al hombre. Y por eso, la que siempre importa a éste de modo absoluto. En realidad, Dios es el hogar más cálido del alma. Cuanto más se adentra el hombre en el misterio divino, más se sacia su corazón, mejor aprecia la bondad, la verdad y la belleza, más preparado se encuentra para amar.

Dios no tiene entidad tan sólo en los pensamientos y deseos humanos. Más bien los pensamientos y deseos humanos poseen la capacidad de abrirse al Creador y constituyen una imagen de su Señor. No son los pensamientos y deseos humanos los que crean a Dios, sino es Dios quien ha creado al hombre con capacidad de pensar, desear e incluso de relacionarse con Él. La apertura a Dios no empobrece las capacidades humanas, más bien las enriquece

\footnotetext{
${ }^{6}$ Las mentes más lúcidas, incluso del pensamiento laico, convergen en afirmar que la religión no está predestinada a desaparecer. Tiene más futuro de lo que algunos piensan (cf. J. HABERMAS, Entre naturalismo y religión [Madrid 2006; Paidós]). Sólo el sectarismo propio del siglo XIX, emergente por desgracia una y otra vez en la actualidad, puede aventurar tal hipótesis de la desaparición del fenómeno religioso en un futuro previsible. El tiempo ha desacreditado tales opiniones, que se han demostrado siempre como falsas y falaces. Nada mejor para desenmascararlas que una vivencia comunitaria sincera del mandamiento nuevo del amor de Jesús.
} 
y, llegado el caso, las plenifica. La estructura humana está diseñada de tal forma que sólo alcanza su meta al abrirse a la Trascendencia.

Digámoslo sin tapujos, sin miedos y sin buscar caer en el imperialismo teológico: el hombre sin Dios no es un hombre completo. Le falta algo, y algo fundamental para el desarrollo de su personalidad, para el logro de su existencia y para la implantación del sentido de su vida. El Creador se ha introducido tan de lleno en la creatura humana, que prescindir de Él significa quedar diezmado en su ser más profundo. Se da una constante presencia de Dios en la vida humana, que sólo los sectarios o desnortados (y pronuncio ambas palabras con el máximo respeto, sin desear ofender a nadie) pueden negar. La verdadera tragedia del mundo moderno, como lo fue la del mundo antiguo descrito por san Pablo en su obra más importante, consiste en negarse a reconocer el papel de Dios en la vida de los hombres, en el entramado vivo de la sociedad y en el sentido del mundo en general (Rom 1,18-32).

Dios no merma, sino acrecienta; no esclaviza, al contrario ¡libera! No puede concebirse como un problema psiquiátrico, sino como la acertada solución a las angustias humanas. Todo esto queremos tenerlo en cuenta aquí, aunque sólo sea como trasfondo. Pero digámoslo claramente: no queremos hablar con un lenguaje inasequible, únicamente reservado para iniciados, sino con un lenguaje sencillo, adaptado a los intereses de los pequeños. «Sólo cuando lo teológico trasciende su lenguaje esotérico y comienza a ser inteligible, se lleva a cabo un proceso de asimilación que la misma teología requiere» ${ }^{7}$. Únicamente así, hablar de Dios puede servir de alimento espiritual para los creyentes de a pie que se esfuerzan por avanzar en su compromiso cristiano.

\section{El Padre de nuestro Señor Jesucristo}

Dios se encuentra en el santuario más sagrado de mi -nuestra- interioridad, pero de verdad ¿puedo - podemos- conocerlo? ¿Tengo-tenemos-acceso a Él? ¿Quien es en realidad Dios? ¿Cómo se manifiesta en mí, en nosotros? ¿Resulta posible mantener con Él un diálogo de amor? El gran valor de Jesucristo consiste precisamente en habernos dado respuesta a todos estos interrogantes y, a la vez, habernos mostrado el auténtico rostro de Dios; primero con el convincente testimonio de su vida y después con el valor de

\footnotetext{
${ }^{7}$ J. Ratzinger, Dios como problema (Madrid 1973; Cristiandad) 14.
} 
sus palabras, cargadas de sinceridad y verdad. Jesús se muestra imprescindible en nuestra vida porque no sólo nos posibilita el acceso a Dios, también nos abre al diálogo de amor con Él en toda su autenticidad. Lo más precioso que nos ha legado Jesús ${ }^{8}$ ha sido el Dios Trinitario: su Padre, un Dios infinito en su amor por el Espíritu.

Si algo está presente en la historia de Jesús es la realidad envolvente de Dios. Actúa en la integralidad de su personalidad de modo tan determinante que constituye el principio primero de todo su ser y hacer. Si quitamos de su vida a Dios no podemos entender nada de lo que es y hace. El Padre constituye su convicción primera, la seguridad inamovible, que condiciona por entero su existencia. En el centro de su vida surgen Dios, su reino, su voluntad, sus valores y prioridades; en definitiva, sus designios de salvación presentes en su misterio insondable para beneficio de la humanidad. Todo lo dispone el Padre con la fuerza de su amor. Su patrimonio reside en Él, así como su patria y hogar. Jesús no sólo habla del Padre, lo siente, lo palpa, lo toca, camina a su lado en el discurrir cotidiano con su aliento invisible pero eficaz. Todo lo puede con Él, nada realiza sin Él, guiado e impulsado como está por la fuerza del Espíritu.

No se trata de buscar a ciegas a Dios, más bien se trata de encontrarlo allí donde se encuentra. Y el lugar mayor donde se nos muestra es en la humanidad de su Hijo. Contemplar a Cristo significa tanto como contemplar al Padre (Jn 14,9). Encontrarse con Cristo lleva consigo encontrarse con el Padre, ya que es el camino que conduce hacia Él (Jn 14,7s). Afirma con contundencia el prólogo del Cuarto Evangelio: «A Dios nadie le vio jamás; el Hijo único que es Dios, y que está en el seno del Padre, nos le ha dado a conocer» $(1,18)$. Este hecho salvífico se alza como la verdad primera, que recorre todo el entramado del escrito joánico.

El seguimiento de Jesús constituye la mejor forma de llegar a la realidad resplandeciente del Padre. Al seguir a Jesús los cristianos damos testimonio de una vivencia y un valor excepcionales: Dios está con nosotros y podemos convertirnos en sus testigos. Estar con Jesús para ser y vivir como Él, adoptar su estilo de vida y proseguir su causa del Reino constituyen la mejor manera de ponernos en camino para experimentar la belleza, grandeza, verdad y bondad de Dios, con todo lo que comportan.

Contemplar las obras de Jesús en su relación con los necesitados, nos sitúa en comunicación directa con el Padre. Leídos en profundidad los evangelios, nos encontramos con la gozosa constatación de que «donde Jesús apa-

\footnotetext{
${ }^{8}$ Cf. Benedicto XVI, Jesús de Nazaret (Madrid 2007; La esfera de los libros) 148s.
} 
rece la gente recupera la esperanza, la ilusión, las ganas de vivir, encuentra sentido en el presente, se siente mejor, consolada y reconfortada. Todos los demonios -lo que les angustia, lo que les impide ser felices, les deprime- desaparecen» ${ }^{9}$. Pues bien, donde Jesús está presente brota también el Padre liberador con toda la fuerza de su gracia.

Y es que el Padre que nos muestra Jesús a través de sus obras no troncha nuestros deseos, sino que les confiere nueva creatividad y les abre a un futuro prometedor; no frustra nuestra sed de felicidad, al contrario, quiere que seamos felices, no sólo en la otra vida, también en ésta; no nos introduce en la depresión, sino que nos comunica alegría existencial, gozo de vivir, fuerza para salir al paso de las dificultades que plantea el diario acontecer.

Cristo desea que vivamos la salvación de la mano del Padre, con la energía que nos proporciona el Espíritu y el testimonio que Él mismo, como Hijo de Dios, nos brinda. El Padre de Jesucristo no niega el yo humano, lo acoge, lo afirma, lo sostiene de forma permanente y lo plenifica, porque tanto Él como el Espíritu tienen como finalidad suministrar vida en abundancia. Ese Padre de los hombres, que nos revela Jesús con el impulso del Espíritu, es el Dios vivo y verdadero, que necesitamos los humanos.

\subsection{El Padre y los hermanos unidos, no separados o enfrentados}

Llegado este momento nos volvemos a hacer una pregunta: $i Y$ cómo se encuentra Dios entre nosotros en Jesús? Como Padre, que nos invita a acogerlo junto con los hermanos. Abrir el corazón a Dios conlleva, al mismo tiempo, abrírselo a los demás. Porque Dios no agota nuestro amor, al contrario lo potencia en su dinamismo más eficaz. No agosta nuestra entrega, más bien la plenifica. Pensar que amar al Padre significa perder a los hermanos no sólo constituye un error de bulto, suena incluso a blasfemia.

Dios, digámoslo una y otra vez en todos los tonos posibles, nos abre a los semejantes como nadie, nos faculta para relacionarnos en su justa medida con los hermanos. De hecho, es el único que nos hace capaces de comprender lo mucho que significa el amor a los demás para la realización de la propia identidad personal. Cuanto más lo amemos a Él y cuanto más amemos a los hermanos, más personas seremos. Además, amarlo a Él sólo resulta posible, cuando se ama a los prójimos, sin exclusión de ninguno (1 Jn 4,19-21).

\footnotetext{
${ }^{9}$ M. Gelabert BAllester, Vivir la salvación. Así en la tierra como en el cielo. (Madrid
} 2006; San Pablo) 28. 
Necesitamos volvernos al Dios de los hombres y para los hombres, que es el Dios, que se desprende de la buena noticia de los Evangelios. Mediante la conversión del corazón urge, por eso, cambiar de Dios, así como suena. Estamos vocacionados para dejar a un lado al dios superfluo de las tradiciones paralizantes, al dios intimista de la burguesía comodona, que nos desliga de los semejantes, para dirigirnos al Padre de Nuestro Señor Jesucristo, que es el Dios vivo y verdadero, inquebrantable defensor de todo lo humano. Sólo fijando nuestra vista en Jesús lograremos contemplar el rostro de su Padre, que nos pregunta por los hermanos y nos impele a que los acojamos, valoremos y amemos en el modo y la media que desea de cada uno.

\subsection{Dios en lo ordinario de lo cotidiano}

Jesús nos enseña algo fundamental: «el Reino de Dios está dentro de vosotros» (Lc 17,21; cf. Q 11,10 = Mt 12,28/11,20). No hace falta que nos desplacemos lejos para encontrarlo, Él se hace presente en lo más íntimo de nuestro interior. No necesitamos hacer cosas fuera de lo normal para contar con su apoyo, ya que nos acompaña en el acontecer diario.

El mayor peligro que puede darse en nuestra espiritualidad consiste en pensar que Dios se encuentra en lo extraordinario, cuando en realidad la llamada a lo extraordinario puede convertirse en una forma indebida para mostrar la incapacidad real del descubrimiento de Dios. Quizá pensemos que la conquista de Dios sólo resulta posible a almas excepcionales como FRANCISCO DE Asís o JUAN DE LA CRUZ en el pasado remoto, o como JUAN XXIII o TERESA DE CALCUTA en el presente próximo. Si el Dios mostrado por Cristo, desea entrañarse en cada persona, ¿cómo podemos pensar así?

Este pensamiento puede ser mortal, ya que lo verdaderamente consolador consiste en que tú y yo podemos tratar con Él cara a cara, aquí y ahora. Cualquier persona de buena voluntad, que desee abrirse a Dios, es capaz de mantener una relación con Él, que puede ser tanto más provechosa cuanto mejor se deje poseer por su presencia y más acepte su actuación invisible. Lo que importa no es vivir lo extraordinario, que no deja de ser excepcional, sino aceptar lo ordinario extraordinariamente bien y estar convencidos que podemos vivir la presencia divina en la cotidianidad del quehacer diario, bien orientado.

No se trata, por lo tanto, de inventarnos otra vida distinta a la que tenemos, de evadirnos en soñados paraísos perdidos y fabricarnos castillos de marfil en el aire, se trata más bien de aceptar la vida tal cual es, se manifiesta y nos toca asumir en su densidad. Es precisamente en esa vida real, no en la 
soñada o inventada, donde se nos muestra la gratificante actuación de Dios. La presencia divina es eficaz, cuando no se hace trampa a la propia vida y se vive en lo que tiene de gratificante, pero también de dureza. En este sentido el ejemplo de Jesús no puede ser más esclarecedor.

Y hay algo más: Los humanos hemos complicado tanto nuestras relaciones personales que Aquel que es la solución a todos nuestros males, lo hemos convertido en problema ${ }^{10}$. Dios como problema, afirmamos en ocasiones con la mayor de las tranquilidades, e incluso con pretensiones científicas, cuando en realidad lo que hace es liberarnos de nuestras tragedias y ayudarnos a pacificar nuestras ansiedades. No veamos a Dios como problema y contemplémosle mejor como la solución más auténtica para nuestra verdadera vida, como la respuesta acertada a los problemas diarios. Algo nuevo y de gran valor nos enseña Jesucristo entonces: a vivir la presencia de Dios en las diversas manifestaciones de lo cotidiano.

\section{Vivir la presencia de Dios: Las distintas manifestaciones de Dios EN LO COTIDIANO}

Nada santifica más que vivir con entera consciencia y con gozo permanente esa presencia divina en la vida diaria. Tenemos que tener la más completa seguridad de que antes que clamemos al Señor el ya está en medio de nuestra vida sustentándonos con la ternura de su bondad. El Tritoisaías lo expresa de forma admirable:

«Entonces clamarás al Señor y te responderá;

gritarás y te dirá: Aquí estoy.

Porque yo, el Señor tu Dios, soy misericordioso» (Is 58,9) ${ }^{11}$.

Lo que proclamó el gran profeta, lo vivió Jesús en toda su intensidad: ese Dios, presente en nuestro deseo y en las obras buenas realizadas a favor

\footnotetext{
${ }^{10} \mathrm{Y}$ lo hemos hecho de manera especial los españoles. Un libro editado por J. RATZINGER, que en su idioma original lleva por título Die Frage nach Gott (La pregunta sobre Dios), el traductor castellano, un buen traductor por cierto, J. M. BRAVo NAVALPOTRO, lo traduce por Dios como problema. La diferencia es bien significativa.

${ }_{11}$ Moisés podía enorgullecerse constatando: «Y en efecto, ¿qué nación hay tan grande que tenga dioses tan cercanos a ella, como lo está el Señor nuestro Dios siempre que lo invocamos?" (Dt 4,7). El Señor Dios de Moisés es el Padre de Jesucristo, que nos ha mostrado la presencia de Dios en tonos insuperablemente íntimos, trascendiendo incluso al gran legislador judío en las afirmaciones anteriores. El Padrenuestro puede ser un buen ejemplo de ello.
} 
de los necesitados (Is 58,6-8), se nos manifiesta de muy distintas maneras en nuestro quehacer de cada día.

Los Discursos de Adiós del Cuarto Evangelio (Jn 14-17) nos proporcionan esta buena noticia: participar de la vida de Jesús por la comunicación del Espíritu supone entrar en una nueva relación con Dios de dimensiones insospechadas. Cada uno de los creyentes, que se mantiene unido al Hijo Jesús, se convierte en morada del Padre. La misma realidad humana, inhabitada por el Espíritu, se acredita como el santuario vivo del Padre del amor:

«El que me ama, se mantendrá fiel a mis palabras.

Mi Padre le amará, y mi Padre y yo vendremos a él y viviremos en él» (Jn 14,23).

El Padre deja de ser un Ser distante y lejano, acercándose al hombre en Jesús hasta el punto de convertirse en una presencia entrañable de ạmor en el mismo corazón humano. Esa comunión funda, al mismo tiempo, la comunión de los hombres entre sí. Y así ese Dios, manifestado en Cristo, se muestra de forma esplendorosa en la oración, en el silencio, en la escucha de la Palabra, en los hermanos encontrados en las múltiples relaciones diarias, en los signos de los tiempos y en el testimonio ante los demás. Explicitamos con detenimiento cada uno de los enunciados:

\subsection{En primer lugar en la oración:}

Una santa de nuestro tiempo ha definido con exactitud lo que significa orar y nos ha dado la razón más profunda por la que podemos y necesitamos la oración, esa «hazaña más sublime de la cual es capaz el espíritu humano»:

«La oración es el trato del alma con Dios. Dios es amor, y amor es bondad que se regala a sí misma; una plenitud existencial que no se encierra en sí, sino que se derrama, que quiere regalarse y hacer feliz. A ese desbordante amor de Dios debe toda la creación su ser. Las creaturas más dignas son los seres dotados de espíritu, que reciben ese amor de Dios entendiéndole y libremente pueden corresponder» ${ }^{12}$.

El hombre, y más el creyente, es ese ser espiritual, que puede corresponder a Dios con su amor. Precisamente en esa correspondencia de amor se

\footnotetext{
${ }^{12}$ E. Stein, Obras selectas (Burgos 21998; Monte Carmelo) 314.
} 
verifica lo más auténtico de la oración, de la que hoy precisamos como en ningún otro momento de la historia, para lograr nuestro anhelado equilibrio interior, tan amenazado por un mundo exterior complicado y en no pocas ocasiones desquiciado. No lo dudemos:

«Necesitamos más que nunca, por lo tanto, equiparnos con la oración para una travesía larga y difícil en medio del mundo, que estrena milenio y que, en muchas capas significativas de la sociedad, vive "como si Dios no existiera". En un contexto así "vivir en y de Dios", en compañía de los hermanos, sólo resultará posible cuando exista una experiencia religiosa personal e íntima, profunda y fuerte, una decisión individualizada y libre por el Otro con mayúscula. Únicamente quien permita nacer a Dios en su interior, quien experimente que Dios es Dios en su vida y le deje actuar como tal en su corazón, permanecerá incólume como hombre religioso, en nuestro caso como cristiano, y comprobará lo decisivo que resulta para su existencia abrir las puertas del alma al Ser que importa e interesa más que nada y nadie.

En este sentido la oración tiene que ser un componente insustituible en el equipaje de viaje de los creyentes. Si queremos ser, de verdad, místicos en el sentido más noble de la palabra, no nos queda otro remedio que ejercitarnos con ahínco y asiduidad en la oración; y, sobre todo, en la oración de contemplación, que es la más perfecta y la que integra todas las demás. Quiero recalcarlo con la máxima seriedad por la trascendencia que tiene: no puede haber auténtica experiencia de Dios sin la práctica permanente de la oración.

Y hasta diría más: sin la práctica de alguna forma de oración contemplativa, que es la que realmente posibilita el encuentro en profundidad con el Padre, el Hijo, el Espíritu Santo ¡y el hombre! La relación inmediata con el Padre, iluminada con el testimonio de Jesús, sostenida por la acción amorosa del Espíritu Santo y verificada en la comunidad de los creyentes, constituye la dimensión absolutamente primordial de la existencia cristiana, que nos permite indagar sapiencialmente en el misterio tanto divino como humano y convertirlo en experiencia personal viva» ${ }^{13}$.

${ }^{13}$ L. Á. Montes Peral, El Padrenuestro. La oración trinitaria de Jesús y los cristianos (Estella 2001; Verbo Divino) 11s. Es bien sintomático que «el primer vagido de la lengua castellana es una oración» (Dámaso Alonso), debida a la pluma de un monje de San Millán de la Cogolla, que comentaba un sermón latino de SAN AGUSTín (cf. J. H. BERMEJO «Ocho siglos más tarde: por los caminos del Mío Cid»: Vida Nueva [20.01.07] 44). Es bien aleccionador constatar que la lengua castellana no empieza su andadura histórica con transacciones comerciales, por ejemplo, sino con la sorprendente apertura de un hombre de esta tierra a Dios. Lo que nos está indicando, de forma bien paradigmática por cierto, dónde sitúa su esperanza el alma castellana. 
Conviene que no olvidemos esas formas de oración tradicionales, que tantos frutos de santidad han dado en el pasado inmediato: el rezo del Oficio de las Horas, sobre todo las Laudes y las Vísperas, la lectio divina, la oración personal intensa, la lectura bíblica con carácter sapiencial. Bien orientadas en el seno de la comunidad, ayudan a un eficaz trato con Dios y a crecer armónicamente en la experiencia religiosa.

Pero siempre teniendo en cuenta algo fundamental, a lo que se ha referido no un teólogo sino un hombre corriente de profunda fe, muy buen literato, que escribió hace más de medio siglo un bello libro sobre el poder de la oración, en la forma de unas cartas dirigidas a su amigo y colega:

«Dios es èl fundamento de nuestro ser. Está dentro de nosotros y enfrente de nosotros. Nuestra realidad es parte de Su realidad que Él proyecta en nosotros a cada momento. Cuanto más profundo es el nivel dentro de nosotros del que brotan nuestras oraciones, tanto más son Suyas, sin dejar en absoluto de ser nuestras. Mejor dicho, son más nuestras cuando son más suyas» ${ }^{14}$.

En la verdadera oración, con su variedad de tonalidades, crece el convencimiento de la presencia de Dios, además se va verificando una fecunda conjunción de voluntades en la que la nuestra se convierte más y más en voluntad divina. Y así podemos experimentar la verdad de la petición de Jesús: «Hágase tu voluntad, en la tierra como en el cielo» (Mt 6,10b). Hace crecer mucho en la oración, contemplar a Jesús orando, ya que Él es el primero y más eficaz Maestro de la verdadera oración. Nadie puede evangelizar nuestra oración como Jesús ${ }^{15}$.

\subsection{En segundo lugar en el silencio interior meditativo ${ }^{16}$}

El mundo actual no aprecia el silencio. Estamos inmersos en una cultura con muy escasa capacidad de escucha. En ella se impone el ruido, la llamada contaminación acústica, la explosión del bullicio sin coto ni límite. Al hombre actual le gusta más hablar que callar, le apetece más rodearse de voces que retirarse a la tranquilidad obsequiosa. La juventud rehúye el silencio, como si se tratara de una peste. Los adultos, inmersos en el tráfago del mundo, se

\footnotetext{
${ }_{15}^{14}$ C. S. LewIS, Si Dios no escuchase. Cartas a Malcolm (Madrid 2001; Rialp) 82s.

15 Cf. L. Á. Montes Peral, Jesús orante. La oración trinitaria de Jesús (Salamanca 2006; Publicaciones Universidad Pontificia) 35-50.

${ }^{16} \mathrm{Me}$ detengo un poco más en este aspecto, porque no suele ser tratado como se debe. Los otros aspectos son más conocidos y existe mucha más literatura escrita sobre ellos.
} 
sienten incómodos cuando cesa la actividad y llega la hora de encontrarse con uno mismo. Hemos acostumbrado a los ancianos a salir de su intimidad, para buscar la máxima exterioridad como expresión de una supuesta calidad de vida. En definitivo el hombre de hoy ha olvidado el silencio, como virtud y como capacidad de crecer en la vida interior y de encontrarse con Dios.

Sin embargo, el silencio, bien entendido y asumido, puede considerarse como un auténtico tesoro. No porque sea un fin en sí mismo, sino porque nos ayuda, de forma muy eficaz, a abrir de par en par nuestro corazón a Dios y a las realidades divinas. Por eso, atrévete: en la quietud contemplativa expresa claramente tu verdad a Dios, tu Amigo y Señor. Estáte seguro que te escuchará y sabrá cambiar tu modo de pensar y actuar, si así conviene a tu salvación y al bien de los demás. Tienes derecho y hasta obligación de ser feliz, así como ayudar a los otros a que también lo sean. Pero piensa en la serenidad que nunca alcanzarás la verdadera felicidad al margen del Padre. Las propias fuerzas, por grandes y persistentes que sean, no bastan aquí. Mediante la acción del Espíritu, únicamente Dios se acredita como la fuente de la dicha y del gozo. Supera la ruidosa confusión de la vida y déjate transformar por el silencio salvífico de la Trinidad, que se comunica contigo en la paz interior y transmite sosiego a tu alma.

Y así, pudiendo hablar, calla ante Dios en actitud reverencial, porque es en el silencio donde mejor se descubre su presencia, aunque esta constatación pueda sorprendernos ${ }^{17}$. Para ello necesitamos incorporar nuestra quietud en la vida trinitaria, insertarnos en el misterio de su amor desbordante y desbordado. Por paradójico que parezca, el silencio eterno se acredita como la eterna conversación existente en la Trinidad, que no necesita de palabras en la expresión de su pensamiento y en la manifestación de su amor. En el silencio agraciado y agradecido percibimos también los hombres el eterno diálogo existente en el seno trinitario. El Padre pronuncia la Palabra que es el Hijo y del amor mutuo entre ambos brota el Espíritu de la Verdad y del Amor, que llena de fecundidad salvífica al silencio.

Quien calla asombrada y agradecidamente sabe que vive de la bondad trinitaria y en ella pone toda su esperanza. Sabe muy bien que necesita cada día de la misericordia del Padre y la acoge con el recogimiento propio de quien conoce el secreto que enriquece por dentro toda su existencia. La bondad y la misericordia divinas, que experimenta en la aquiescencia de su corazón le sitúan en el camino hacia lo bueno, él mismo se hace bueno, por estar en comunión íntima con el que «sólo es bueno» $(\mathrm{Mc} 10,18)$.

\footnotetext{
${ }^{17}$ Cf. J. Rof CARBallo, Entre el silencio y la palabra.
} 
El silencio adquiere así una finalidad religiosa primaria, digna de atenderse como se merece y también necesitada de ser educada en la forma debida. Efectivamente, en toda vida humana existe un espacio interior, donde crece y se desarrolla lo más propio del yo, que es precisamente donde se verifica el encuentro con Dios mediante el silencio sonoro, que deja respirar al ser en sus mayores y más íntimas ultimidades. En este aquiescente encuentro con el Absoluto se manifiesta la autenticidad, libertad, fidelidad y honradez humanas, que son imagen del Dios sentido, acogido, valorado y gozado. En ese silencio interior crece el amor de quien se siente amado y con capacidad también para amar. Este silencio interior puede prender en todas las situaciones de la vida diaria y se va haciendo más frecuente, cuanto más experiencia vivida se tiene de él.

Desde luego, el silencio no lo es todo, pero constituye una base fundamental para hacer posible el crecimiento en la experiencia divina. Donde mejor resuena la voz de Dios es en la gran calma del silencio. El talante y el gusto por lo divino, y en su complementación por todo lo verdaderamente humano, crece precisamente en la quietud del espíritu, en el recogimiento íntimo. Éste, sólo posible al hacerse silencio, nos permite descubrir mejor las verdaderas perspectivas de la realidad, que tiene su origen en Dios y en Él encuentra su primer fundamento básico. Vivir la realidad primera no nos distancia de las cosas, más bien nos ayuda a contemplarlas en la debida dimensión, a valorarlas en su justa medida.

El verdadero silencio, por lo tanto, no aísla, al contrario abre a la inmensidad de Dios, permite abismarnos en su infinita misericordia, que excede todo peso y medida. Cuando se ha divisado el horizonte infinito, que descubre el amor divino, no resulta posible ya el distanciamiento de lo verdaderamente humano. Ordenarse hacia Dios significa, al mismo tiempo, disponerse para los semejantes, ser ganado para los auténticos intereses humanos. La soledad de Espíritu no encierra en uno mismo, posibilita como nada el encuentro con el hermano, experimentando la realidad divina.

Necesitamos, por lo tanto, espacios de silencio, practicar el ayuno de las palabras, para dejar resonar en lo profundo la Palabra viva, que se siente en el interior sin ser pronunciada. El silencio puede así iluminar y enseñar al creyente en su camino hacia la plenitud divina. No olvidemos nunca que Dios es Palabra viva, sí, como acabamos de constatar, pero es también verdadero escondimiento. «Sólo cuando lo hemos conocido como silencio, podemos esperar oír también su hablar que emana de su silencio» ${ }^{18}$.

${ }^{18}$ J. RATZINGER, Por qué estamos aún en la Iglesia. (Citado por Alfa y Omega $\mathrm{n}^{\circ}$ 579/7II-2008, 10). 
En el silencio místico el hombre encuentra el fundamento de su existencia, percibe como en ningún otro lugar el ansia de plenitud, que sólo puede ser saciada por la realidad infinita de Dios. En su día el gran poeta hindú Rabindranath TAGORE escribió estos hermosos y certeros versos:

El agua en el vaso se llena de destellos,

el agua del mar es oscura.

La pequeña verdad tiene palabras claras,

la gran verdad pide grandes silencios ${ }^{19}$.

¡Si de verdad queremos experimentar a Dios, antes de nada hemos de tomar en serio la decisión de callar! Hablar más allá del exceso, hablar para captar lo que importa de modo absoluto, en realidad, significa callarse, por paradójico que parezca. Sólo el silencio, que después de hace palabra y testimonio, es capaz de descubrir las profundidades divinas, que anidan en la Trinidad Santa. La ya citada E. STEIN ha escrito sobre «el diálogo solitario con Dios» estas admirables palabras:

«En el eterno silencio de la vida intradivina, se decidió la obra de la redención. En lo oculto de la silenciosa habitación de Nazaret vino la fuerza del Espiritu Santo sobre la Virgen que oraba en la soledad y realizó la encarnación del Redentor. Reunida en torno a la Virgen que oraba en silencio, esperó la Iglesia naciente la nueva infusión del Espíritu, que la debía vivificar para una mayor claridad interior y para una acción exterior fructuosa» ${ }^{20}$.

Por eso, sacando conclusiones del comportamiento divino, que podemos hacer nuestro, antes de nada, hablar es callar. Quien, asentado en el amor de

\footnotetext{
${ }^{19}$ Citado por P. LAÍ́ ENTRALgo, Idea del hombre (Barcelona 1996; Círculo de Lectores) 197.

${ }^{20}$ Edith StEIn, Obras Selectas, o. c., 403. A través de una intensa experiencia mística, una testigo casi de nuestro tiempo, SOR ISABEL DE LA TRINIDAD, beatificada por Juan Pablo II en 1984, ha puesto de manifiesto que no puede existir recogimiento interior sin darse una serie de condiciones, que ella explica de forma muy bella: «Para que nada me obligue a salir de este hermoso silencio interior, he de conservar siempre la misma actitud, el mismo aislamiento, la misma separación, el mismo desprendimiento. Si mis deseos, mis temores, mis gozos o sufrimientos; si todos los actos que proceden de estas cuatro pasiones no están perfectamente ordenados a Dios, no seré un alma solitaria. Habrá alboroto en mí. Por lo tanto necesito el sosiego, el sueño de las potencias, la unidad del ser», en «Últimos ejercicios espirituales. Día décimo», Obras Completas (Burgos 41984; Monte Carmelo) 180. «El alma que ha penetrado en la fortaleza del santo recogimiento se halla en idéntica situación (= las cosas exteriores no son capaces de hacerla salir de su sagrado silencio). Iluminada su inteligencia por la luz de la fe, descubre a su Dios presente y viviendo en ella» (ibídem, Día segundo, 164). Cf. R. DE LA CRUZ, «Sor Isabel y el recogimiento interior»: Teresa de Jesús 143 (2006) 197-200.
} 
Dios, descubre en su vida el valor inconmensurable del silencio, hace posible la transformación de su interior, que le llevará al cambio de vida. Cambiar la mente, renovar los hábitos, acertar en la búsqueda de la felicidad, conseguir aquello que se busca con sinceridad y empeño, sólo resulta posible, cuando se apuesta en libertad por el recogimiento íntimo, que proporciona la vida interior.

En este sentido, María puede acompañarnos, ya que se acredita como una Maestra consumada del silencio contemplativo (Lc 2,19.51). Es ella, al mismo tiempo, quien mejor supo testimoniar a Dios ante los demás. Expresión suprema de ese fecundo testimonio es su canto del Magníficat, sólo posible de pronunciar, cuando antes se ha tenido un dilatado tiempo de recogimiento interior, contemplando el paso de lo divino por la historia de la salvación, convertida en propia historia personal ${ }^{21}$. El silencio le ayudó a centrar su corazón en Dios y abrirse a los dones de la salvación.

\subsection{En tercer lugar en la apertura atenta a la Palabra de Dios}

De lo afirmado en el apartado anterior, deducimos que urge recuperar la dimensión inherente a la calma meditativa, ya que silencio y escucha caminan juntos. Resulta imposible escuchar sin tener capacidad de quietud interior. Sin esa interioridad, que no es intimismo ensimismado y estéril, sino aptitud para la apertura y la acogida, nunca podrá darse una adecuada percepción de la Palabra divina. Empecemos entonces por acallar voces, por apartarse de los ruidos en los momentos propicios, para lograr así una verdadera actitud de escucha y acogida. La escucha de la voz divina necesita del requerido silencio, para poder ser percibida de modo conveniente. Sin recogimiento y sosiego interior difícilmente puede percibirse lo que el Padre nos muestra en la expresión de su voluntad, tal como se encuentra en la Palabra de vida y salvación.

Es un hecho que necesitamos tiempo, serenidad y recogimiento interior para escuchar la Palabra, de manera que en esa escucha pueda prender la experiencia cotidiana de Dios, tal como la encontramos en la Biblia y en los textos litúrgicos de cada día. Llegado el caso, también, en la ya mencionada lectio divina. La Palabra de Dios está pronunciada para informar nuestra vida

${ }^{21}$ Al hilo de la mariología, no hace mucho escribí una sencilla reflexión teológica sobre el silencio interior, que quisiera citar aquí por la importancia que tiene, según mi entender, para crecer en la experiencia de lo divino, objeto directo de lo que ahora estamos abordando (L. Á. Montes Peral, En la entraña de la mariología [Burgos 2006; Monte Carmelo] 269-272). 
entera, ya que constituye el verdadero alimento espiritual, que vigoriza nuestra fe, espolea nuestra esperanza y nos alienta para entregarnos a los demás en la práctica del amor. La voz del Padre la encontramos, de forma preferente y suprema, en las enseñanzas de Jesús, recogidas en los evangelios, convertidos para siempre en Palabra de vida.

La Palabra contiene la revelación de Dios, en la que nos habla de tú a tú, nos descubre nuestra identidad y nos confronta con nuestro destino, dándonos a conocer su voluntad como camino hacia la plenitud. La Palabra actúa así en cada historia propia y nos muestra los designios salvadores divinos. Nuestra postura, por lo tanto, postula la acogida de esa Palabra bendita a través de la fe, como respuesta libre y consciente que nos lleva a la comunión y diálogo con el Altísimo. Para el verdadero creyente la Palabra de Dios se convierte en el primer principio de la realidad. De hecho, el creyente es aquel en el que la Palabra cala tan hondo en su vida que le presta más verdad que las mismas cosas que percibe por los sentidos.

La escucha de la Palabra ofrece dos dimensiones complementarias: la personal, íntima y la litúrgica, comunitaria, que encuentra su expresión cumbre en la celebración de la Eucaristía. Las dos se entretejen y determinan mutuamente. Abrir los oídos a los designios divinos, que se expresan en su Palabra, constituye una forma segura de experiencia de Dios, que nos ayuda a descubrir la voluntad divina allí donde en realidad se manifiesta de modo privilegiado y, a su vez, nos guía hacia el testimonio ante los demás. Así entendida, la Palabra significa lugar de encuentro con Dios mediante la acogida y la alabanza, la obediencia y la fidelidad.

Meditar, saborear e interiorizar la Palabra de Dios puede obrar maravillas en los discípulos de Jesús. Nunca estarán mejor preparados para acoger a Dios en el santuario del corazón, que cuando dejan impregnar todo su ser con el fecundo agua de la voz divina, que resuena en la Palabra. Nunca podrán presentar a Dios a los demás de forma más certera, que cuando se equipan con la Palabra de Dios, reverenciada, anunciada y testimoniada.

\subsection{En cuarto y preferente lugar en el encuentro con los hermanos, de un modo especial las victimas y los humillados de este mundo}

Es en ellos donde Dios se nos manifiesta de una manera muy señalada. Para el creyente no resulta posible la relación amorosa con los otros sin la mediación de Dios, que es Padre -de-los-hombres-y-para-los-hombres. De hecho, la paternidad divina fundamenta la fraternidad humana. En realidad sólo la paternidad divina posibilita la comunión fraterna en su más auténtica ex- 
presión. Lo encontramos magníficamente expresado en el Padrenuestro. Atendiendo a las intenciones de Jesús, la experiencia religiosa se realiza y verifica en el trato con los hermanos. Ellos constituyen el lugar insustituible del encuentro con el Padre. Son muchas las presencias, que Dios nos media en los prójimos necesitados, para que lo encontremos en ellos. El Padre nos invita a acoger a los hermanos, allí donde se encuentran. Sólo así podremos, a su vez, encontrar al Padre y testimoniarlo «en Espíritu y Verdad».

Pero algo tiene especial relevancia: Dios se encuentra de un modo especial al lado de las víctimas y abomina de los verdugos, que producen dolor injusto y se apoyan en el poder bruto y la violencia injustificada para humillar a los pequeños. El Padre de Jesucristo se abaja hasta las víctimas de la clase que sean, les muestra su misericordia y les ofrece su protección. Y quiere hacerlo a través de los que creemos en Él. Quiere que cada uno de nosotros le prestemos nuestro cuerpo, nuestras manos, nuestras fuerzas, nuestra valentía para compadecernos de ellas, hacer de la compasión principio de actuación y ayudarlas a salir de su postración, hasta el punto de considerarles como objeto preferente de nuestro amor, ya que en ellos se manifiesta Dios y el Cristo doliente.

Quien se sitúa al lado de los oprimidos injustamente, se pone de parte de Dios y está siendo testigo de su amor en el mundo. Quien grita contra los que humillan y desprecian la dignidad humana, está prestando su voz al Padre compasivo. Quien opta eficazmente por los atribulados y explotados de la tierra está diciendo sí al Altísimo y cumpliendo su voluntad. Dios mismo está caminando a su paso y no le faltará la ayuda de su gracia. En los pobres se capta al Padre que nos habla en su revelación, situándose de su parte (Q 10,21 = Mt 11,25-26;/ 10,21). En los pequeños se puede pensar, sentir, vivir y testimoniar con mayor fidelidad al Dios del amor, ya que en ellos se manifiesta con toda la fuerza, llama a la conversión e invita al cambio de vida y situación tanto personal como comunitario.

En el semblante deformado de las víctimas, los humillados y maltratados por los fanatismos, la violencia y el terror se transparenta el rostro mismo dolorido del Crucificado, que está pidiendo a gritos justicia para los inocentes, dañados como están, de forma injusta, en su calidad humana. No olvidemos que muchos hombres hoy mueren torturados y asesinados contra toda equidad. Millones y millones sufren la lenta crucifixión que produce la injusticia estructural generalizada, el capitalismo salvaje que sólo busca el propio interés y no contempla las necesidades ajenas.

Entregarse a los pobres constituye una forma segura de llegar a Dios y poderlo servir con eficacia. En el tú del hermano necesitado tocamos la humanidad del mismo Hijo. El hombre pregunta muchas veces, dónde está Dios, 
sin percibir el interrogante del Padre, que nos apremia: ¿dónde está tu hermano? Cuando respondemos a la interpelación divina tenemos garantizada la presencia de Dios en nuestra vida.

En los inocentes oprimidos, en los despojados de su dignidad humana se hace presente el Padre de la compasión y la misericordia por medio de su Hijo crucificado con toda la fuerza y la verdad de su sangre derramada para nuestra salvación. El Padre del Crucificado está unido para siempre a las víctimas. Los creyentes tenemos en ellas un lugar privilegiado para el encuentro con Dios. Donde más se muestra el amor desbordante divino es en la Cruz de Cristo, convertida desde entonces en la de todos los crucificados del mundo.

\subsection{En quinto lugar, en los signos de los tiempos}

De ellos ha hablado certeramente el Concilio Vaticano II. Podemos leer en el Libro de la Creación cómo Dios se encuentra vivo y actuante en todas las realidades terrenas. Un gran místico de nuestra Edad de Oro lo muestra con toda rotundidad y ha añadido un pensamiento muy fecundo acerca del despertar al amor de Dios:

«Cada mañana hallarás, ánima mía, a la puerta de tu casa a todo el Universo, las aves, animales, campos y cielos, que te esperan para servirte, para que tú pagues por todos el servicio del amor libre, que tú sola en lugar de todos debes a tu Criador y suyo. Todas las cosas te despiertan al amor de tu Dios, y todas como un procurador de su Señor, te ponen demanda de amor. Convídante a su amor el clamor grande de todas sus criaturas, así superiores como inferiores, las cuales con voces manifiestas te declaran su majestad, su hermosura y su grandeza» ${ }^{22}$.

Pero también en las interrelaciones humanas más hondas podemos contemplar el paso de Dios por el espesor de la vida y hacer de ellas una lectura teológica de la realidad. El Concilio nos indica con realismo:

«Las personas y los grupos sociales están sedientos de una vida plena y de una vida libre, digna del hombre, poniendo a su servicio las inmensas posibilidades que les ofrece el mundo actual. Las naciones, por su parte, se esfuerzan cada vez más por formar una comunidad universal» ${ }^{23}$.

\footnotetext{
${ }^{22}$ Fray Diego de Estella, Del Amor de Dios (Clásicos de Espiritualidad Cristiana; Majadahonda [Madrid] 2002; Yatay) 31s.

${ }^{23}$ LG 9,4.
} 
En esas aspiraciones universales, y en otras muchas que se podían nombrar, obra Dios, que desea lo mejor para la humanidad entera y quiere que los hombres, cómo no también los creyentes, trabajemos por la consecución de una tierra nueva y una sociedad renovada, abierta a todos en sus bienes y promesas. Tales anhelos, que anidan en lo más noble del corazón humano, se ajustan por completo a los planes divinos sobre los hombres y los cristianos estamos llamados a hacerlos nuestros, ya que Dios los sostiene y les confiere el incremento debido con nuestra colaboración. En ellos podemos descubrir entonces la acción del mismo Dios.

Pero para poder llevar a efecto tales aspiraciones y anhelos necesitamos discernir con métodos adecuados el modo concreto de conseguir lo que de positivo se esconde detrás de esos deseos profundos, siempre con la ayuda de la gracia y en sintonía con todos los hombres de buena voluntad, que ajustan su comportamiento a los designios de lo alto. Estamos llamados a tener los ojos muy abiertos para traducir en esperanza todo ese caudal de riqueza humana, que se expresa en la sociedad de hoy y que es mucho más grande que lo negativo que también crece en ella.

Uno de los signos de los tiempos más enraizados en la actualidad y que mayor discernimiento necesita, es la llamada globalización, con los aspectos positivos y negativos que le acompañan. En ella nos acompaña Dios ¡y cómo! En la medida que ponemos la economía, la política, la cultura, los valores sociales al servicio de la persona humana, creada a imagen y semejanza divina y llamada a ser hija de Dios, está actuando Dios en la vida de los demás y también en la propia. En la medida que la verdad, la justicia, el amor y la misericordia, plasmados en los derechos de todos, sobre todo de los más pobres y necesitados, se va haciendo presente la soberanía divina en el mundo, reconocible a los ojos creyentes. Nuestra pequeña o grande aportación puede tener repercusiones universales, porque detrás de ella se alza el incremento que Dios confiere a quienes actúan en su nombre y con su gracia hacen el bien ante los demás.

En los inicios del Nuevo Milenio el Papa y los obispos europeos descubrieron, con perspicacia evangélica, estos signos de los tiempos que se van enraizando de forma muy positiva en nuestro continente:

«Comprobamos con alegría la creciente apertura recíproca de los pueblos, la reconciliación entre las naciones durante largo tiempo hostiles y enemigas, la ampliación progresiva del proceso unitario de los países del Este europeo. Reconocimientos, colaboraciones e intercambios de todo tipo se están llevando a cabo, de forma que, poco a poco, se está creando una cultura, más aún, una conciencia europea, que esperamos pueda suscitar, especialmente entre los jó- 
venes, un sentimiento de fraternidad y la voluntad de participación. Registramos como positivo el hecho de que todo este proceso se realiza según métodos democráticos, de manera pacífica y con espíritu de libertad, que respeta y valora las legítimas diversidades, suscitando y sosteniendo el proceso de unificación de Europa. Acogemos con satisfacción lo que se ha hecho para precisar las condiciones y las modalidades del respeto de los derechos humanos. Por último, en el contexto de la legítima y necesaria unidad económica y política de Europa, mientras registramos los signos de esperanza que ofrece la consideración dada al derecho y a la calidad de la vida, deseamos vivamente que, con fidelidad creativa a la tradición humanista y cristiana de nuestro continente, se garantice la supremacía de los valores éticos y espirituales» ${ }^{24}$.

Indudablemente en ese conjunto de signos de esperanza, que se dan en nuestro entorno de hoy, podemos descubrir la actuación del mismo Dios, que nos lleva por caminos de la salvación. Trabajemos por discernir esos signos de manera que, como quieren el Papa y nuestros obispos, se garantice la supremacía de los valores éticos y espirituales, de acuerdo con la voluntad divina. No reduzcamos la Europa de los pueblos a un mero intercambio de bienes económicos y culturales, con miras más o menos egoístas. Europa contará con la bendición divina, cuando no se encierre en sí misma, y ayude a los demás continentes a salir de su postración y a participar de los mismos dones que desea para ella. Aquí encontrará su grandeza.

\subsection{Y por fin, en sexto lugar, en el testimonio ante los demás}

No basta con creer en Dios. No basta tampoco con experimentarlo en la propia vida. También estamos llamados, como lo hizo de forma esplendorosa Jesús, a testimoniarlo en la sociedad y el ancho mundo. Hoy más que nunca, se impone la virtud de la parresía, con los que los creyentes constantemente nos encontramos por los caminos de la vida. Y llamamos aquí parresía al testimonio público, solemne, valiente y entusiasta delante de los demás, de que Dios vive y transmite la salud a los hombres que se dirigen a Él.

Llamamos parresía, del mismo modo, al testimonio gozoso e ilusionante de que nuestra vida depende sobre todo de un Dios bueno, abierto de par en par a las necesidades humanas, que nunca deja en la estacada a su ser más querido, al contrario, le acompaña en el camino y le lleva a la plenitud. De un

\footnotetext{
${ }^{24}$ Juan Pablo II, Exhortación apostólica postsinodal «Ecclesia in Europa», nº 12.
} 
Dios solícito que desea la fraternidad entre los hombres como elemento necesario, para que podamos mirar con esperanza al presente y futuro de la humanidad. Nuestra existencia, vivida con autenticidad, alumbra al Dios escondido en su creación y en las interrelaciones personales.

Es el Espíritu quien nos proporciona el don de la parresía, para vivir desde Dios y para manifestarlo con el entusiasmo propio del que está totalmente satisfecho con su vida, porque en el centro de ella se encuentra el que le proporciona sentido, le lleva por el buen camino y le abre a la verdad, la bondad y la belleza. El Padre de Jesucristo, nuestro propio Padre, no sólo es justo y bueno, también es bello y está cargado de verdad.

No olvidemos nunca: Dios se manifiesta a través de los testigos. Y nuestro testimonio, por lo tanto, puede facilitar el encuentro de otros con Dios. Es verdad que en su radicalidad sólo Dios puede darse a conocer a sí mismo. Pero los que nos esforzamos por conseguir la experiencia de Dios podemos servir de intermediarios, para que la presencia divina se haga operante en los humanos de buena voluntad. Sin duda este hecho constituye algo muy gratificante, pero también significa un compromiso, cargado de responsabilidad, que bajo ningún concepto podemos eludir. Conscientes de este empeño se nos exige convertirnos en heraldos de Dios, mensajeros de su buena noticia con el ejemplo de la propia vida, propagadores de su causa por vocación y convicción.

El día del Seminario del año pasado tuvo este lema: Sacerdotes, testigos del amor de Dios. Pero no sólo los sacerdotes y los que se preparan para este ministerio, también los religiosos y los fieles comprometidos están llamados a adoptar esa actitud confesante de lo que significa vivir del milagro del amor divino. En este sentido el mejor testimonio que podemos dar es ayudar al prójimo a solventar sus necesidades en nombre del Dios del amor, del que BENEDICTO XVI está hablando, día tras día, con tanto convencimiento testimoniante.

En algunos momentos puede cundir entre nosotros el desánimo. Y pensar que testimoniar a Dios representa una empresa poco menos que irrealizable, ya que resulta imposible darlo a conocer con nuestras pobres vidas. Pero no es así. Nuestro testimonio puede ser veraz y estar lleno de vigor y esperanza con la ayuda de la gracia. Lo que nos permite permanecer hermanados en incesante actividad con actitudes esperanzadas. A pesar de la propia pequeñez, el que con libertad y parresía actúa de forma generosa en favor de los demás, habla con elocuencia de Dios en este mundo, que parece replegado sobre sí mismo e incapaz de salir de su egoísmo. Ante el Dios que es Amor desaparecen los desánimos, amanece el reconocimiento del otro y surge el futuro espléndido de la fraternidad. Delante de la presencia de Dios, 
todo lo que existe en nosotros de arrogante se convierte en humildad, la lacra del egoísmo da paso a la entrega desinteresada en favor de los necesitados y tambaleantes.

¡Merece la pena proseguir en el testimonio por pequeño que sea! ¡Merece la pena apasionarse por Dios en el servicio gratuito a los demás! ¡Merece aún más la pena hacerlo en un mundo que parece sólo entender la pasión en el sentido carnal! No nos podemos conformar con lo adquirido, instalarnos en lo de siempre. ¡ Con la ayuda del Espíritu es posible testimoniar a Dios más y mejor! ¡Podemos alumbrarlo en los demás mediante las obras de amor! En el momento presente los cristianos, que creemos y experimentamos al Padre de Jesucristo, nuestro propio Padre con todas las garantías de la mayor verdad, tenemos un reto sagrado, que un excelente conocedor de estos temas ha formulado con acierto así:

«testimoniar con nuestra forma de vivir, la belleza, el valor, la verdad y la bondad del Dios en que creemos, y mostrar que, más allá de la tolerancia, el cristianismo es para nosotros fuente de solidaridad con toda la familia humana» ${ }^{25}$.

En pocas palabras, ésta puede ser nuestra gran misión hoy: vivir la bendición que supone realizarse personal y comunitariamente en la presencia divina delante de los demás con obras de amor, sobre todo a los necesitados; tal tarea, realizada con el entusiasmo del que se entrega a los demás en nombre de Jesucristo, constituye el mejor lenguaje sobre Dios, que puede llegar de forma eficaz a nuestros semejantes. Dejemos que Dios se revele a través de nuestra vida, que actúe en nosotros, como Él sabe hacerlo, así podrá hablar con eficacia también en los demás. Demos la palabra a Dios con la expresión de un testimonio sencillo y sincero en favor de nuestros hermanos los hombres.

\section{INVITACión A ADENTRARNOS EN EL MISTERIO DE DIOS}

El hombre moderno ha descubierto muchas cosas y ha avanzado en lo técnico hasta lo insospechado. Pero parece que todos esos descubrimientos y avances están volviéndose contra él, porque no encuentra un punto de apoyo donde asentarlos. Ha olvidado a Dios, principio y fundamento del ser

$$
\text { 2007) } 37 \text {. }
$$

25 J. MARTín VELASCO, «Un escaparate laico para las religiones»: $R S 21$ ( $\mathrm{n}^{\circ} 896 ;$ Febrero 
humano, y de ahí derivan muchos de sus males. Descartado el Creador, las creaturas pierden su sentido. Abandonado el Padre, el verdadero amor se pervierte. Cuando muere Dios en el corazón del ser humano, también mueren los hombres.

Por eso, necesitamos volver de nuevo a Dios. Hablar de Él, porque es Alguien que nos interesa vitalmente. Desearlo, porque nuestra felicidad se encuentra en sus bondadosas manos. Experimentarlo en la propia vida con la avidez del que busca sentido. Testimoniarlo ante los demás, para mostrar nuestras señas de identidad. Todo lo que sea explicitar, exponer, proponer, explicar a Dios; todo lo que nos lleve a conocerlo mejor, percibirlo en el silencio interior, encontrarlo en los hermanos, atisbarlo en los signos de los tiempos, nos hará mejores personas, nos permitirá volvernos más felices y contribuirá a hacer un mundo más cálido, en el que haya lugar para todos los seres de la creación, de modo especial para los hombres.

Atrevámonos a dejar que la divinidad de Dios tome posesión de nuestra vida, nada malo puede ocurrirnos con ello. Al contrario, el abrirnos al misterio divino, el adentrarnos en el milagro de su amor, tal como ha sido revelado por Cristo Jesús, siempre constituye fuente de bienes para los demás y para nosotros mismos. Dios ayuda al hombre a enfrentarse consigo mismo, con los demás y con el mundo en que vive. Le ayuda a pensar, sentir, razonar y vivir mejor la relación propia, con los demás y con la naturaleza. Dios le ofrece caminos de salvación, que le permiten realizar todas sus potencialidades humanas.

Es tarea ineludible de todo cristiano, consciente de su vocación en la Iglesia y de su misión en este mundo, dejarse conducir por el Padre de Nuestro Señor Jesucristo, acoger el amor inmenso e incondicional que nos tiene, que siempre se vuelve mayor cuanto más lo experimentamos. La Trinidad Santa que nos revela Jesús, tiene mucho que decir al hombre de hoy, de modo especial al creyente, que ha entrado en el Tercer Milenio del cristianismo. Está a nuestro lado y camina con nosotros en diversidad de presencias, que podemos reconocerlas siempre que abramos las antenas de la mente, practiquemos la mística de los ojos abiertos y tengamos el corazón bien dispuesto para la acogida gozosa.

Los inicios del Nuevo Milenio constituyen un tiempo privilegiado para atreverse a adentrarse en la experiencia divina. ¡Atrevámonos entonces a acoger al Dios de la misericordia y la compasión que sale a nuestro encuentro! ¡Dejemos que el Espíritu nos inhabite para percibir la gracia divina! Él vive a nuestro lado, quiere hacer camino con nosotros, como personas nuevas, renovadas por dentro mediante la gracia de su amor. No lo olvidemos: o vivimos de arriba para los demás o sucumbiremos en las profundidades de la destrucción. 
No podemos rebajar a Dios hasta el punto de convertirlo en un instrumento a nuestro antojo, o separarlo de nuestra vida como algo inútil, sin valor alguno. Siempre su soberanía estará por encima de los intereses humanos. Pero tampoco podemos desconocer que Dios quiere hablar con cada uno, que su pasión somos nosotros y que no nos deja nunca de su mano, aunque nosotros nos desembaracemos de Él. Es a ese Dios gratificante y plenificante al que hemos de preparar una morada digna en nuestro interior, para luego poder ofrecérselo a los demás. El silencio, bien orientado, siempre encuentra interlocutor: el Dios del amor, que espera paciente la reacción que tengamos a su Palabra de verdad.

En estas premisas descubrimos un reto: ¡Hablemos, experimentemos y testimoniemos a Dios hasta el final, hasta llegar al extremo! Estoy seguro que no nos arrepentiremos de ello. El Padre de Jesucristo interpela nuestra mente, enciende nuestro corazón, radicaliza nuestra actuación. Pensarlo, sentirlo, vivirlo constituye el más preciado de los bienes.

La verdadera espiritualidad se acredita como una demasía. Pero una demasía necesaria, para que el hombre pueda saciar su sed de felicidad en una sociedad infeliz. Una demasía pertinente, para que la persona llegue a realizarse en todas sus potencialidades ilimitadas. Una demasía factible, ya que Dios que lo trasciende todo y va más allá de lo que podemos sentir, pensar y expresar sobre Él, se encuentra también en lo más íntimo del corazón humano, en lo más entrañado del pensamiento y en lo más preciado de su acción. Una demasía resistente, que sabe que sólo Dios permanece y se sitúa de su lado, a pesar de todos los pesares, porque en Él el hombre se juega el futuro.

En realidad sólo se puede pensar, sentir y amar, pensando, sintiendo y amando en Dios. Esto que puede parecer otra demasía, incluso una falacia, constituye una verdad primera y el fruto granado del que no se contenta con migajas y aspira al logro total de la vida humana. Cuando uno se apasiona por la búsqueda de la verdad, se adentra en la espesura de la belleza y ansía la bondad atreviéndose a amar hasta las últimas consecuencias, no lo dudemos que se encuentra con el exceso plenificante que es el Dios desvelado en nuestros pensamientos, sentimientos y comportamientos.

¡Ciertamente Dios es exceso y demasía! Pero un exceso y una demasía que cuando se gustan sitúan al hombre en el camino del llegar a ser lo que aún no es, pero está llamado a ser en sus ansias de plenificación. Conocerse a uno mismo, realizarse hasta el final, únicamente resulta posible cuando el horizonte Dios está a la vista, cuando el Padre de Jesucristo nos acompaña, cuando su Espíritu guía nuestros pasos e inspira nuestras actuaciones. Dios significa la mejor explicación del hombre. Sólo Él basta y sobra, para hacer- 
nos hombres de verdad y para abrirnos a la dicha a la que cada hombre está destinado.

\section{FINAL:}

En este tiempo de gracia que nos toca vivir podemos escuchar en nosotros el mismo mensaje que escuchó María: «Alégrate, llena de gracia, el Señor está contigo». ¡Ojalá esta buena noticia encuentre en nosotros parecida resonancia a la que tuvo en la Madre de Jesús! Alégrate, quien quieras que seas. Estás lleno de gracia, ya que el Señor se encuentra a tu lado, quiere relacionarse contigo y darte el don de su amor incesante.

Aquí y ahora se nos hace una llamada a la alegría en su más firme fundamento. Estamos convocados a acoger la invitación al júbilo, que nos llega desde lo alto, a no dejar pasar la ocasión propicia que se nos brinda. ¡Alegrémonos tú y yo! No lo dudemos: cada uno de los oyentes de la Palabra puede sentir el gozo de la salvación, si así lo desea. Todos nosotros somos seres agraciados, porque Dios se fija en cada uno con la inmensidad de un amor real y verificable.

La razón por la que podemos gozarnos es bien clara: cada uno de nosotros somos seres agraciados, nos invade la misericordia entrañable de la Trinidad, su ternura infinita, su compasión sin límites. El Padre de los cielos sale a nuestro encuentro, se nos autocomunica donándose Él mismo y quiere mantener con nosotros un diálogo de amor. Por puro regalo podemos vivir como verdaderos hijos suyos en el Hijo y como hermanos entre los hermanos. Toda una buena noticia, que puede transformar, con el impulso vivificador del Espíritu, nuestra vida por dentro y nos convierte de verdad en personas nuevas, transidas por dentro y por fuera de felicidad.

Aquí y ahora la Trinidad, el Dios cristiano, está entre nosotros y volcada con nosotros. Nos acompaña siempre de modo incondicional el Padre por el Hijo en el Espíritu. El Padre nos concede su bondad única como nadie se puede imaginar. El Hijo humanado nos la testimonia con el ejemplo de su vida y la verdad de sus palabras. Nos invita a adentrarnos en el misterio insondable del amor divino: ¡Atrévete a hacer de ese amor el valor supremo de tu existencia! El Espíritu nos posibilita a experimentar ese amor filial como realidad primera de nuestro ser y quehacer.

Las palabras de aceptación de María: «Hágase en mí, según tu palabra» pueden ser en este momento nuestras propias palabras. Mi decisión -nuestra decisión- ha de consistir en acoger al Padre, que sale a mi -a nuestro- encuentro. Desde el silencio reverencial y gozoso podemos aceptar la invita- 
ción a vivir el desbordante amor trinitario, hasta el punto que vaya creciendo en cada uno como experiencia interior y nos conforme progresivamente como ministros de ese amor ante el mundo.

Acogido el mensaje de forma vital, María testimonió a Dios como nadie lo ha hecho, se entregó a la obra de la salvación en favor de todos los hombres con una fidelidad encomiable y con una eficacia que el paso del tiempo ha demostrado hasta qué alturas llegó. La experiencia de la Trinidad puede hacer de nosotros testigos del Padre de nuestro Señor Jesucristo, ayudando a que las personas con las que nos encontramos sean transformadas, porque se han encontrado con el Dios del amor, mediado en su vida con nuestra ayuda.

El momento presente no puede ser desperdiciado; se acredita como «kairós» de gracia y de salvación. El aquí y ahora de nuestra existencia en este mundo está llamado a convertirse para nosotros los creyentes en una revelación del amor del Padre a la humanidad, en una historia del amor de Jesucristo a todos los hombres de buena voluntad y en una manifestación del amor mutuo que los humanos nos tenemos, porque poseemos el Espíritu. Ese amor del Padre, del Hijo y del Espíritu pertenece, por gracia divina, a todos los hombres, también a cada uno de nosotros. Estamos vocacionados para acogerlo, vivirlo y testimoniarlo. 